1 Secretaria de Estado de Saúde de Minas Gerais (SES-MG) - Belo Horizonte (MG), Brasil.

Orcid: https://orcid org/0000-0002-8219-

9230

acastrohadad@gmail.com

2 Universidade Federal de Minas Gerais (UFMG),

Faculdade de Medicina,

Departamento de

Medicina Preventiva

e Social (MPS) - Belo

Horizonte (MG), Brasil.

Orcid: http://orcid.

org/0000-0003-1366-

1732

alzira.o.jorge@gmail.com

\section{Continuidade do cuidado em rede e os movimentos de redes vivas nas trajetórias do usuário-guia}

\author{
Network care continuity and living network movements in user-guide \\ paths
}

Ana Carolina Amaral de Castro Hadad', Alzira de Oliveira Jorge $\mathbf{2}$

DOI: $10.1590 / 0103-11042018 S 416$

RESUMO Com a mudança do perfil epidemiológico e demográfico no nosso País, a capacidade das Redes de Atenção à Saúde de garantir o acesso e a continuidade de cuidados a usuários egressos de internações hospitalares com necessidades de cuidados na rede tem se tornado um grande desafio. Buscando descrever e analisar os encontros entre atores da produção de cuidado, que refletem em movimentos de redes vivas e potencializam a continuidade do cuidado e a integralidade, uma usuária egressa de internação hospitalar foi acompanhada pelo período de 6 meses tendo como referencial metodológico o usuário-guia. Por meio de entrevistas em profundidade, foi reconstituída a trajetória dessa usuária buscando a continuidade do cuidado pós-alta. As narrativas foram analisadas por meio de Análise Temática de Bardin, em que foram evidenciados momentos de redes vivas e, em outros, falta de rede, que impactaram em barreiras dificultadoras de acesso. Conclui-se que, na riqueza dos encontros, as redes vão se construindo, em momentos, com maior força e potência que em outros. Esses momentos podem impactar diretamente no desfecho dos casos, como o da usuária acompanhada. Necessário investir na formação dos trabalhadores para práticas integrais em saúde que considerem o usuário como protagonista do seu cuidado.

PALAVRAS-CHAVE Integralidade em saúde. Continuidade da assistência ao paciente. Redes de saúde comunitária.

ABSTRACT With the change of the epidemiological and demographic profile in our Country, the capacity of Health Care Networks to guarantee access and continuity of care to users coming from hospital admissions with care needs in the network has become a major challenge. Aiming to describe and analyze the meetings between actors of care production, that reflect in movements of living networks and potentiate the continuity of care and integrality, a user coming from hospital admission was monitored for a period of 6 months having as methodological reference the user-guide. Through in-depth interviews, the trajectory of this user was reconstituted seeking continuity of post-discharge care. The narratives were analyzed through Bardin's Thematic Analysis, in which moments of living networks were evidenced and, in others, lack of networks, which impacted on barriers that made access difficult. It is concluded that, in the richness of the meetings, the networks are being built, in moments, with greater strength and power than in others. These moments can have a direct impact on the outcome of the cases, such as the patient's follow-up. It is necessary to invest in the training of workers for integral health practices that consider the user as the protagonist of their care.

KEYWORDS Health integrality. Patient care continuity. Community health networks. 


\section{Introdução}

Segundo Pinheiro et al. ${ }^{1}$ obras que buscam estudar a relação dos usuários com os serviços de saúde ainda são escassas, tendo em vista a importância do tema. Considerando um contexto social, cultural, econômico e um projeto político institucional, esses autores definem o conceito de demanda em saúde, que surge por meio das interações dos sujeitos (usuários, profissionais e gestores) na sua relação com a oferta de serviços de saúde.

Segundo Cecílio² ${ }^{2}$ necessidades em saúde são tramadas nos múltiplos encontros do trabalho em saúde, no embate das muitas vozes sociais que se colocam como enunciadoras de demandas. Quando essas vozes são ouvidas e se deixam escutar, o processo de produção das necessidades tende a ganhar potência. As demandas podem ser, então, compreendidas como solicitações dirigidas aos serviços de saúde, no sentido do direito.

As necessidades de saúde são social e historicamente determinadas ou construídas. Cecílio $^{2}$ salienta que, para um indivíduo alcançar suas necessidades de saúde, precisa: ter boas condições de vida; ter acesso e poder consumir toda a tecnologia de saúde capaz de melhorar e prolongar a vida; ter vínculos afetivos de referências e confiança nos profissionais de saúde; e ter graus crescentes de autonomia no seu modo de levar a vida.

A compreensão das necessidades de saúde dos usuários ou de um coletivo requer capacidade de escuta, respeito à diversidade humana, cultural e social e, ainda, compreensão para além do processo saúde e doença. A capacidade e a disponibilidade dos profissionais de se implicarem com as questões trazidas e de reconhecerem o usuário enquanto agente ativo na produção de sua saúde são essenciais no encontro entre os agentes envolvidos no processo de cuidar. Esses são os encontros produtores de cuidados ${ }^{3}$. Segundo Merhy, Feuerwerker e Cerqueira ${ }^{3}$, o mundo do cuidado é um terrítório que pertence a todos os atores das ações cuidadoras. Ele é configurado a partir do trabalho vivo em ato e da articulação de saberes que não dizem respeito à razão ortodoxa da clínica. É nesse território, a partir das mútuas afetações, que se produzem os encontros e a possibilidade de uma construção negociada por meio de afetos e interesses, pois aí é que se faz valer a autonomia dos usuários e que se torna possível articular o trabalho da equipe de saúde.

Na busca da resolução de suas necessidades de saúde, sentidas e vividas por cada usuário, estes constroem uma trajetória na rede considerando suas condições sociais, culturais e o acesso aos serviços para a resolução dos seus problemas de saúde. Nesse contexto, os usuários são redes vivas de si próprios, já que estão o tempo inteiro produzindo movimentos, elaborando saberes, construindo e partilhando cuidados. As redes estão em constante transformação, pois vão, em acontecimentos, sendo tecidas. O saber do usuário e o seu caminhar pela rede, com seus encontros e desencontros, falam de uma multiplicidade de vidas que vazam dos sinais que vêm da rua, e o mais importante é que os profissionais de saúde, ao convidarem um usuário para entrar em seu consultório, convidem também toda a vida que ele traz da rua para entrar junto ${ }^{4}$.

Merhy e Cecílio ${ }^{5}$ definem as Redes de Atenção à Saúde (RAS) como um campo por vezes informal, atravessado por múltiplos circuitos e fluxos de usuários, que são inconstantes, dependentes de protagonismos e interesses plurais que não devem responder necessariamente a uma única 'racionalidade institucional ordenadora'. As redes estão em constante construção e ofertam diferentes ações e serviços de saúde que são acessados de diferentes maneiras de acordo com as possibilidades e necessidades de cada indivíduo.

O conceito de redes vivas, apresentado por Merhy et al. ${ }^{4}$, aponta a ideia de mobilidade, protagonismo do usuário e da desterritorialização. Faz um convite ao olhar integral e holístico do profissional de saúde, integrando o saber do usuário e sua percepção sobre o processo saúde-doença, reconhecendo e valorizando 
a existência de um 'agir leigo' produtor de mundos, quase sempre invisível ou não valorizado por gestores e pofissionais.

Movimentos ou momentos de redes vivas são marcados pela produção do cuidado em ato, por meio do trabalho vivo e da trajetória desses protagonistas por caminhos nem sempre formais, proporcionando o desenho dos fluxos e a formação de uma 'malha de cuidados ininterruptos'. Possibilitam aos usuários mobilidade e flexibilidade em múltiplas entradas na rede, em uma perspectiva horizontal e circular, de acordo com suas necessidades e acessibilidade ${ }^{4}$.

As redes instituídas por sistemas regulatórios através de fluxos hierarquizados são, em geral, redes fragmentadas, que não dialogam e não priorizam as necessidades dos usuários. Construídos de modo duro, esses sistemas podem ter como efeito a não implicação do trabalhador com o resultado do trabalho e podem produzir a não rede, a descontinuidade do cuidado ${ }^{6}$.

Na saúde, não existe um único caminho a seguir, uma direção que possa ser dada a todas as pessoas, pois uma mesma queixa pode produzir necessidades diferentes. Entretanto, é importante deixar claro que, apesar de não ser possível saber o caminho de cada um, para cada situação há uma gama de possibilidades, incluindo o acesso a diferentes tipos de tecnologias que poderão ser necessárias e devem estar disponíveis. Contudo, isso ainda não garante que as pessoas terão o acesso no momento que precisam.

Segundo Mattos ${ }^{7}$, mais do que um termo designado a representar um dos princípios do Sistema Único de Saúde, a integralidade expressa uma das bandeiras de luta do movimento sanitário. No que diz respeito às relações entre profissionais de saúde e usuários, relaciona-se a uma prática integral: a atenção focada no indivíduo, na família e na comunidade; a visão holística do ser humano, e não em um conjunto de partes; a valorização da história de vida que carrega o usuário, tirando o foco das práticas voltadas à doença; a compreensão da inserção de cada indivíduo num dado contexto familiar, social e cultural; e o reconhecimento da importância do diálogo, permitindo o protagonismo dos diversos atores envolvidos.

Tais práticas favorecem a atenção às diversas demandas dos sujeitos, independentemente do nível de complexidade, e contribuem para um cuidado responsável, continuado ${ }^{8}$.

Atendendo ao que foi acima exposto, este trabalho se justifica pela relevância de se investigar a continuidade do cuidado, possibilitada por movimentos de redes vivas, vividos e sentidos nas relações entre usuários e profissionais de saúde e a oferta de serviços no atendimento nas RAS de Belo Horizonte, município que possui um sistema de saúde consolidado, no qual $85 \%$ da sua população é coberta pela Estratégia Saúde da Família. Ademais, existem portarias ministeriais que indicam um caminho de acolhimento, responsabilização e cuidado integral no âmbito das RAS.

Considerando o modelo instituído de rede e as relações usuário x profissional de saúde, a continuidade do cuidado é um desafio para a garantia da integralidade. Visando a compreender a dinâmica do trabalho vivo e do protagonismo de usuários e trabalhadores em um contexo de rede instituída, este estudo tem como objetivo descrever e analisar os encontros entre atores da produção de cuidado que refletem em movimentos de redes vivas e potencializam a continuidade do cuidado e a integralidade.

\section{Métodos}

Este estudo é produto das discussões apresentadas em dissertação de mestrado, no Programa de Promoção da Saúde e Prevenção da Violência da Faculdade de Medicina da Universidade Federal de Minas Gerais (UFMG) ${ }^{9}$. Foi realizado um estudo qualitativo, descritivo e analítico, cartografando os diversos encontros realizados por usuários em busca da continuidade do cuidado. No trabalho original, a análise originou 5 categorias 
temáticas, e, neste artigo, serão apresentados, para análise e discussão, dados referentes à tematica proposta para esse trabalho.

Em consideração aos preceitos éticos, este trabalho teve a apreciação dos Comitês de Ética da Prefeitura Municipal de Belo Horizonte e da UFMG, CAAE: 011408.1.0000.5149. Os indivíduos sujeitos da pesquisa tiveram todas as suas dúvidas esclarecidas e foram submetidos à assinatura do Termo de Consentimento Livre e Esclarecido (TCLE), como previsto pela Resolução no 466/12 do Conselho Nacional de Saúde?

O referencial metodológico que norteou a pesquisa foi o da cartografia, utilizando o conceito ferramenta do usuário-guia, ${ }^{6,10}$, que valoriza o protagonismo dos atores dos processos de cuidado em saúde e seus encontros no caminhar pelas redes formais ou informais. Sob a perspectiva dos sujeitos, realizou-se a análise desses encontros e da existência de movimentos de redes vivas que potencializaram o acesso aos serviços da rede ou a interação entre os equipamentos sociais e estações de cuidado que favorecem a continuidade do cuidado integral.

Nessa perspectiva, observa-se a definição de um mapa de cuidados que ressalta como o usuário vive, por onde circula, o que ele considera importante. Os modos de existência do usuário são tão ou mais importantes para o cuidado do que o seu diagnóstico, assim como a maneira que as equipes de saúde decidiram cuidar ${ }^{10}$.

O município de Belo Horizonte foi cenário da pesquisa. O trabalho original teve como campo de estudo três Unidades Básicas de Saúde (UBS) que tiveram vinculação com os dois sujeitos da pesquisa. Para apresentação deste artigo, utilizar-se-ão os achados de um dos sujeitos, uma usuária idosa, com comorbidades pré-existentes e que se encontrava em situação de saída de um grande hospital de Belo Horizonte, cuja admissão se deu por causa associada ao trauma. Essa usuária teve alta hospitalar com diversas demandas de reabilitação e cuidado na rede.

Os sujeitos escolhidos para a dissertação de mestrado foram usuários que mobilizaram muito as equipes por conta do alto grau de complexidade dos casos, não só na necessidade de disponibilizar uma série de recursos e tecnologias para o tratamento, mas, também, e principalmente, por exigirem a mobilização de vários tipos de saberes, tanto os saberes de distintos profissionais, como, também, o saber dos usuários e familiares. Este trabalho se debruçará sobre as particularidades do caso da usuária Sra. Maria (nome fictício), devido à possibilidade de melhor exploração da riqueza do caso e seus movimentos de rede.

A análise documental se deu por meio de prontuários eletrônicos, receitas médicas, orientações da equipe multidisciplinar, sumários de alta e relatórios de transferência relacionados ao período de janeiro de 2015 a janeiro de 2016, a fim de analisar a vinculação com as Equipes de Saúde da Família (EqSF)e as ações de promoção da saúde ou tratamento relacionadas às suas condições de saúde.

Durante o período de janeiro a junho de 2016, foi realizado acompanhamento por meio da metodologia do usuário-guia, sendo realizadas entrevistas em profundidade com a filha, principal cuidadora da usuária, pois esta apresentava um grau elevado de sequelas após a alta hospitalar, sem condições de interação e realização de entrevista. As entrevistas foram realizadas em sua residência e gravadas. Por meio destas, foi possível reconstituir a trajetória da usuária e de seus familiares em busca da continuidade do cuidado após as altas hospitalares.

A primeira entrevista em profundidade realizada foi orientada pela seguinte questão norteadora: 'você/seu familiar sofreu um acidente, ficou internado e recebeu alta com necessidades de tratamentos e cuidados. Como está sendo tudo isso para vocês?'. Considerando a metodologia utilizada, durante a coleta de dados, foram acompanhadas todas as interações do usuário e dos familiares com os diversos equipamentos formais, informais e sociais da rede, na busca do cuidado, incluindo entrevistas e conversas com trabalhadores dos serviços por ela utilizados. As demais 
entrevistas foram livres, e, de acordo com o desdobramento do caso e as necessidades da usuária/familiar, foi avaliada a perspectiva quanto aos acessos, como produção de vida e barreiras existenciais, que vão além de algo físico-geográfico.

A análise qualitativa do material coletado nas entrevistas foi feita por meio da técnica de análise de conteúdo temático, considerando os referenciais teóricos sobre integralidade, continuidade do cuidado e redes vivas. Bardin ${ }^{11}$ descreve o método da Análise de Conteúdo como um conjunto de técnicas de análise das comunicações que utiliza procedimentos sistemáticos e tem como objetivo a descrição do conteúdo das mensagens. Essas técnicas devem ser aliadas à inferência do pesquisador durante o estudo dos conteúdos e buscam descobrir os núcleos de sentido que compõem uma comunicação na tentativa de compreender o pensamento do sujeito por meio do conteúdo expresso no material em análise ${ }^{\mathbf{1 2}}$. A análise documental foi categorizada e será apresentada em corroboração aos achados da análise de conteúdo.

\section{Resultados e discussão}

A seguir, será apresentada a reconstrução da história de vida da Sra. Maria, com a riqueza dos pontos de vista trazidos pelas narrativas dos sujeitos, complementados, coletados nos documentos 'oficiais'.

A Sra. Maria tem 62 anos, é casada, mãe de 3 filhas, do lar, moradora de um bairro do Distrito Sanitário Oeste, onde residia com o marido, ex-taxista, portador de glaucoma, que está desempregado. Segundo conta uma das filhas do casal, a Sra. Maria estava com a situação cadastral do Cadastro de Pessoas Físicas (CPF) desatualizada e não era contribuinte do Instituto Nacional do Seguro Social (INSS); por sua vez, o seu marido não conseguiu a aposentadoria por invalidez requerida devido à perda visual que vem apresentando, e recorreu à justiça. Dessa maneira, os dois não tinham renda fixa. Dependiam da ajuda das filhas para o sustento.

A usuária era portadora de Hipertensão Arterial Sistêmica e Diabetes Mellitus tipo II descompensados, tabagista pesada, além de ter depressão e ansiedade, segundo foi informado pela filha. Desde 2014, teve diversos atendimentos registrados, sempre realizados pelos mesmos profissionais, geralmente o médico e a enfermeira da EqSF da unidade.

Em todos os atendimentos realizados, há relato da história pregressa da usuária, acrescentando-se, ainda, o fato de ser obesa e dislipidêmica. Em diversos registros de atendimentos, sua pressão arterial se encontrava elevada, sempre próxima de 170, a sistólica, e 100 a diastólica, em média. Não há registro de aferição de glicemia capilar.

Há registro do acompanhamento da equipe por meio de consultas realizadas nos meses de fevereiro, abril, maio, agosto, outubro e dezembro de 2014, além de janeiro, abril e agosto de 2015. No dia 27/10/2015, a usuária deu entrada no Hospital João XXIII, trazida pelo Serviço de Atendimento Móvel de Urgência (Samu), após queda de 07 degraus com perda de consciência. A filha entrevistada e também os demais familiares acreditam que a queda pode ter sido causada por um descontrole pressórico e frisam o fato de que, apesar de a mãe fazer acompanhamento na UBS há bastante tempo, seus níveis pressóricos nunca tinham estado estáveis antes da sua internação no Hospital de Trauma da cidade.

Teve alta no dia 01/12/2015, mantendo estabilidade hemodinâmica, com controle dos níveis pressóricos e glicêmicos, orientações para dieta e encaminhamento para reabilitação com cuidados de fisioterapia, fonoaudiologia e nutrição na UBS. A usuária apresentava sequelas importantes, não estabelecia contatos, acamada, portadora de lesão por pressão em região sacral e totalmente dependente de cuidados.

Após a alta hospitalar, a usuária foi encaminhada para o Centro de Saúde onde residia uma de suas filhas. As filhas tomaram essa decisão pela pouca estrutura da residência da 
Sra. Maria e a pouca capacidade do seu esposo em cuidar dela, por ele também ser idoso e estar necessitando de cuidados.

Segundo relato da filha, a assistente social do hospital orientou a família a fazer o cadastro da usuária no novo centro de saúde assim que eles informaram a decisão da mudança de endereço e orientou quanto à obtenção de cadeira de rodas.

A família teve muita dificuldade de adaptação à nova realidade, tanto financeira, quanto no tocante aos cuidados realizados com a usuária. Nos primeiros dois meses após a alta, ela morou na casa de uma das filhas, sendo cuidada pela família da filha. Esta é diarista e trabalha em regime de plantão; tem dois filhos adolescentes, que moram na casa. A tia dos meninos contou durante a entrevista que, em período de férias, eles cuidaram da avó nos dias em que a mãe estava trabalhando.

Após ter completado 27 dias de alta hospitalar, a paciente teve a sua primeira consulta médica domiciliar. Nesse momento, foi solicitada a avaliação da fisioterapia pela médica da equipe. Quarenta dias após a alta hospitalar, a fisioterapeuta do Núcleo de Apoio à Saúde da Família (Nasf) realizou visita domiciliar acompanhada da Agente Comunitária de Saúde (ACS) da equipe. A profissional indicou reabilitação em nível secundário, no Centro de Referência em Reabilitação Física (Creab) Leste, local distante da residência.

A usuária não conseguiu comparecer à fisioterapia, que foi recomendada duas vezes por semana. A família já apresentava muitas dificuldades para deslocar a idosa dentro da própria casa e para levá-la a consultas na unidade, que ficava no mesmo bairro. Em se tratando de bairros diferentes, a dificuldade era ainda maior.

Insatisfeitos com o Centro de Saúde e com os atendimentos prestados, que, segundo a filha, não eram suficientes para atender às demandas da sua mãe, a família decidiu retornar com a usuária para o bairro e a UBS de origem, após dois meses de alta hospitalar. No período, há relato de atendimento da assistente social do Centro de Saúde do local de origem da Dona Maria, informando ter sido procurada por uma das filhas da usuária, com solicitação de agendamento de consulta médica e de fisioterapia.

A consulta médica se realizou 8 dias após o atendimento de acolhimento da assistente social e 62 dias após a alta hospitalar, o médico da sua EqSF a atendeu durante o acolhimento, não sendo possível a visita domiciliar. Nos dois meses seguintes, a usuária teve em sua residência um atendimento da fisioterapeuta e outro da nutricionista da equipe.

No dia 20/04/2016, a Sra. Maria faleceu em casa após um mal súbito. Estava acompanhada por uma das filhas e pelo genro, foi atendida pelo Samu e teve o óbito atestado pelo médico EqSF. A evolução médica informa o preenchimento da declaração de óbito. Não conseguiu ser reabilitada, mantinha as debilitações físicas, a incapacidade de falar, as mesmas dificuldades com relação à nutrição e constipação intestinal, ainda sem cadeira para banho e com a família comprando quase todos os seus medicamentos de uso diário.

Sua situação cadastral na Receita Federal ainda estava pendente, a solicitação de Benefício Assistencial para Pessoa com Deficiência junto ao INSS ainda não tinha sido realizada e, segundo o relato da filha, considerando o momento da alta hospitalar até o dia do seu falecimento, não houve melhora do seu quadro, e, sim, regressão no grau de debilitação física. A paciente faleceu apresentando afasia como sequela do trauma e engasgos, que haviam sido relatados pela família à nutricionista e à fisioterapeuta. O profissional fonoaudiólogo não chegou a atender a usuária.

\section{Os encontros produtores de cuidados como movimentos de redes vivas}

Considerando o relato do caso da Sra. Maria, a seguir, a análise dos dados documentais e das narrativas possibilitou a definição de alguns núcleos temáticos para a discussão do trabalho original. Vários foram os fatores 
que influenciaram o caminhar da usuária e de seus familiares na busca do cuidado e o seu desfecho. Entre eles, ressaltam-se para esta discussão: a vinculação com as EqSF; a satisfação e a confiança da usuária/familiares e as condições de acesso aos serviços de saúde; a continuidade do cuidado; e a implicação dos trabalhadores de saúde com as necessidades integrais da usuária.

\section{VINCULAC̣ÃO COM EQUIPES DE SAÚDE DA FAMÍLIA, SATISFAC̣ÃO E CONFIANC̣A DA USUÁRIA/FAMILIARES}

De acordo com Brasil13, a Política Nacional de Atenção Básica tem entre os seus fundamentos e diretrizes a adscrição dos usuários e o desenvolvimento de relações de vínculo e responsabilização entre as equipes e a população, garantindo a continuidade das ações de saúde e a longitudinalidade do cuidado. Em outras palavras, implica ter relações tão próximas que fazem com que o profissional se coloque no lugar do usuário e se sensibilize com seu sofrimento, responsabilizando-se e possibilitando uma intervenção pautada nessa relação. Por outro lado, o usuário, cria um elo de confiança com o profissional que é terapêutico.

Veras et al. ${ }^{\mathbf{1 4}}$ ressaltam que uma assistência qualificada é pautada em valores como a confiança e a vinculação. A manutenção de tais valores requer o estabelecimento de um percurso assistencial, com continuidade do cuidado e atendimento a necessidades de cada indivíduo, de maneira integral.

Lima et al. ${ }^{15}$ afirmam que, no encontro entre trabalhador de saúde e usuário, sempre haverá intenções depositadas, em ambos os lados, recheadas de expectativas e trocas. Esse é um espaço de produção de saúde que tem brotamentos de grande riqueza. Esses mesmos autores ${ }^{15}$ discorrem sobre os 'maus encontros' entre usuários e trabalhadores e a organização dos serviços de saúde, que, muitas vezes, não são pautados na escuta qualificada, no acolhimento e no estabelecimento de vínculos. Os serviços estão se tornando mecanizados, produtores de humilhantes filas para acesso aos serviços de saúde, em todos os níveis de complexidade.

A seguir, relatos da filha da Sra. Maria que demonstram insatisfação e insegurança na relação com as EqSF que cuidaram da sua mãe:

[...] Tá. É... nós fizemos essa mudança mesmo, né, de um bairro, de um posto para o outro por falta de atendimento no outro posto, por ela já morar aqui, né, no bairro, e o outro posto era o posto do bairro da minha irmã, né... E, quando percebemos que lá ela não tava tendo cuidado, que não tinha respaldo nenhum, aí, depois de dois meses, com uma única consulta, né, aí foi que nós fizemos a escolha que voltar com ela para o posto dela, né, onde que ela mora, já era atendida, acompanhada pelo médico. Só que agora numa nova história. [...]. (Entrevista da filha da paciente Maria, do dia 22/01/2016).

A filha da usuária fala de uma grande preocupação da família em sentir-se apta a prestar os cuidados que a usuária necessita, já que não conseguiu os cuidados necessários para a reabilitação de sua mãe. Afirma que, nesse sentido, em nenhum momento se sentiram acolhidos em nenhuma das duas unidades nas quais a paciente foi atendida. $\mathrm{E}$ disse, ainda, que o sentimento "é de desamparo", quanto à "morosidade", que é muito grande.

[...] Tudo muito complicado, desde o momento que ela saiu do hospital. E aí ela foi para a casa da minha irmã, porque ela mora ela e meu pai, mas não foi pra ficar com o meu pai porque meu pai também não ia dar conta... E a gente faz o que acha que tá certo, porque a gente não tem um acompanhamento [...]. (Trecho da entrevista da filha da usuária Maria, de 21/01/2016).

[...] os cuidados que gente conseguiu foi por estar buscando, comprando, ligando pra ONG e tentando pedir alguma coisa, mas também o que nos foi informado é que tem muita gente acamada e que a demanda de maca, as cadeiras de rodas, 
essas coisas assim, a demanda tá muito grande, e que o acesso a essas coisas é difícil, até fralda mesmo, você não tem um lugar que alguém te fale, 'olha tem tal lugar assim assim, que que vai te ajudar' [...]. (Trechos da entrevista da filha da usuária Maria, do dia 12/04/2016).

O caso acima descrito bem demonstra que, a despeito da existência incontestável de um direito inerente ao cidadão, amplo e genérico, na prática, não se pode dizer que há integralidade no serviço, que muitas vezes limita-se a atendimentos insuficientes, que não geram resolução de todas as necessidades de saúde, com descontinuidade de cuidados. A despeito do artigo 18 da Lei $n^{\circ} 8.080 / 90$, os familiares contaram que coube a eles arcar com medicação, fraldas, 'almofada' para prevenção de lesão por pressão. Há, ainda, o agravante de que, em um grande município como Belo Horizonte, há fluxos estabelecidos para a disponibilização desses equipamentos/insumos dentro dos programas prioritários, e as informações devem ser oferecidas pelos profissionais, independentemente de em que local o usuário acesse a rede. Na narrativa da filha da Sra. Maria, percebe-se uma grande falha nesse sentido: "você não tem um lugar que alguém te fale: 'olha tem tal lugar assim, que vai te ajudar'”.

Ela afirma, ainda, que o atendimento das necessidades de saúde da sua mãe é um direito e que, muitas vezes, no serviço público, quando se depende de pessoas para ter acesso ou garantia da resolução de um problema, a situação pode ser complicada ou morosa. Segundo ela, porque as pessoas "complicam o que poderia ser fácil" e tratam o direito como se fosse "um favor".

A fragilidade do vínculo terapêutico entre EqSF e usuários é explorada por Lima et al. ${ }^{15}$ quando afirmam que essa relação se repercute nas práticas. As relações pautadas pela fragmentação e superespecialização profissional, maneira hegemônica de organização dos serviços na atualidade, desconsideram muitas dimensões de sofrimento, autonomia e emancipação do usuário e contribuem para que ocorram maus encontros.

\section{A CONTINUIDADE DO CUIDADO E IMPLICAC̣ÃO DOS TRABALHADORES DE SAÚDE QUANTO ÀS NECESSIDADES INTEGRAIS DA USUÁRIA}

Pela sua consolidação no território, que favorece a construção de vínculo e incentiva a responsabilização da equipe quanto às demandas trazidas pelos usuários, a Atenção Primária à Saúde deve ser a ordenadora do cuidado e coordenadora das RAS no âmbito do Sistema Único de Saúde.

A partir da análise qualitativa das particularidades do caso da Sra. Maria, pode-se inferir que há fragilidade na continuidade do cuidado e, como bem colocam Cunha e Giovanella ${ }^{16}$, as falhas nos processos podem se dar pela não implicação e responsabilização profissional, pela falha na comunicação e, também, por problemas estruturais no sistema.

A produção do cuidado que se dá em ato, nos encontros tramados na trajetória desses protagonistas, muitas vezes, é feita por meio de caminhos nem sempre formais, proporcionando o desenho dos fluxos e a formação de uma 'malha de cuidados ininterruptos'. Essas são as redes vivas, que possibilitam aos usuários mobilidade e flexibilidade em múltiplas entradas, em uma perspectiva horizontal e circular ${ }^{5}$. A continuidade dos cuidados, de acordo com as necessidades dos indivíduos, dá-se quando a organização dos serviços e o agir de cada trabalhador respeitam as diversidades e promovem o acesso nos pontos de atenção da rede.

O conceito de longitudinalidade tem sido estudado por muitos autores. Tal termo, que é referenciado na Política Nacional de Atenção Básica, tem sido considerado característica central e exclusiva dessa política. Para Cunha e Giovanella ${ }^{16}$, trata-se do acompanhamento do usuário ao longo do tempo pela EqSF, através do vínculo instituído em que estão implícitas uma relação terapêutica caracterizada por responsabilização por parte do profissional de saúde e a confiança por parte do paciente. Possibilita a atuação nas ações de promoção da saúde, prevenção, cura e reabilitação, 
produzindo diagnósticos e tratamentos mais precisos, além da redução dos encaminhamentos desnecessários, tanto para especialistas quanto para a realização de procedimentos de maior complexidade.

Já a continuidade do cuidado estaria relacionada ao acompanhamento multiprofissional de um determinado problema de saúde e a sucessão de eventos entre uma consulta/atendimento e outros. Depende da transferência de informações para subsidiar decisões com relação ao tratamento, não sendo um elemento característico da atenção primária e, sim, de articulação em rede ${ }^{16}$.

A seguir, relatos da filha da Sra. Maria que nos indicam fragmentação do cuidado e nos remetem à importância de se ampliarem as discussões na rede sobre como se recebe e quais condições de acesso se consegue oferecer para esses usuários e famílias que têm tantas necessidades a serem ouvidas e situações a serem resolvidas.

[...] ela estar internada no João XXIII foi um facilitador, foi um ponto positivo. Que lá ela teve os cuidados necessários, atenderam ela muito bem! Internada, dentro de uma unidade hospitalar, já lá dentro, mas depois que saiu é que você tem que pedir por uma consulta médica, por uma visita de um fono, de uma fisioterapia, disso tudo. É tudo muito complicado [...]. (Trecho da entrevista da filha da Sra. Maria, do dia 11/04/2016).

Outra questão apontada é o acesso às consultas com o profissional fisioterapeuta, um gargalo nas equipes do Nasf em Belo Horizonte e de extrema importância para a reabilitação do usuário no seu pós-alta. A usuária demorou quase dois meses para ter a primeira consulta com a fisioterapeuta do Nasf, e as consultas seguintes foram mensais. Considerando a perda de momento terapêutico ocasionada pela demora decorrida entre a alta e a primeira consulta e as sequelas instaladas na paciente, a sua filha questiona a frequência de visitas da fisioterapeuta:
[...] Olha, pra você ver, eu acho muito difícil. Você não tem acesso a uma fisioterapeuta! Uma vez na semana, que eu acho que deveria ser o mínimo para ver. Uma vez no mês, eu acho que é assim, pouquíssimo, pelo estado dela. Ela está com os joelhos duros, não anda! Essa fisioterapeuta fazer essa visita domiciliar uma vez no mês é muito pouco. E se a gente tiver que levar numa unidade de fisioterapia 3 vezes na semana, 2 vezes na semana, uma vez na semana, o quanto difícil vai ser isso pra uma paciente acamada? Você deslocar uma paciente acamada 1 vez na semana que fosse, pra um local de fisioterapia? [...].

Mais duas situações são importantes de serem citadas com relação à continuidade do cuidado no caso da Sra. Maria. A primeira se trata da grande insatisfação da família com um problema que a paciente enfrentou durante $o$ período de pós-alta até o óbito, quase 6 meses depois, sem que houvesse solução ou implicação de algum profissional para trazer alguma resposta ao problema.

Se trata da constipação intestinal, provavelmente causada pela restrição da usuária ao leito, aliada ao efeito de medicamentos e sequela do traumatismo craniano. Em todas as entrevistas com a filha, esse assunto foi abordado e tratado como um tópico sem solução. A paciente foi acompanhada por duas EqSF, já chegou a ficar 14 dias sem evacuar, já precisou passar por um pronto atendimento devido a um fecaloma e, em nenhum desses serviços, houve orientações ou prescrição de um laxante.

A usuária esperou quatro meses por uma consulta com a nutricionista e, nesse período de espera, a família não se sentiu acolhida e sentia falta de orientações nutricionais:

[...] Alimentação a gente fica super inseguro, porque a gente não sabe muito. Ela até teve uma constipação esses dias com... porque acamada, sem ter esse acompanhamento de fisioterapeuta, e a gente tudo muito no sufoco. A comida é pastosa. E a gente faz o que acha que tá certo, porque a gente não tem um acompanhamento [...]. (Trecho da entrevista da filha da paciente Maria, do dia 22/01/2016). 
No que diz respeito à perspectiva da filha da paciente Maria sobre o acesso e a continuidade do cuidado que as equipes ofereceram à sua mãe, ela acredita que a mãe não foi bem atendida pelas EqSF e que, dessa maneira, não alcançou todas as possibilidades de evolução que alcançaria se estivesse recebendo os estímulos adequados e acompanhada a contento pela equipe. Conforme ilustrado pelos trechos das narrativas acima, a filha se queixou da dificuldade de acesso para todas as necessidades e os encaminhamentos que foram realizados.

[...] Não. Porque o que eu sinto, eu sinto que se ela tivesse tido um acompanhamento desde o começo, eu acho que ela teria evoluído, né? Em algumas coisas que a gente não sabe lidar. Então, eu acho que ela conseguia dar uns passos com o nosso auxílio no começo, e agora a gente vê que ela não faz isso mais. Então, assim, eu acho que a gente realmente perdeu, porque a gente tava tentando fazer as coisas, mas naquela insegurança também, né? Será que eu posso, será que tá certo, então, assim, como ela não teve esses acompanhamentos, eu acho que ela não evoluiu em nada, né? A gente é que que continua aí, tentando fazer o que a gente acha que tá certo [...]. (Trecho da entrevista da filha da paciente Maria, de 11/04/2016).

[...] Não aconteceu, né? (consulta de fisioterapia) Ela teve, no primeiro posto, 1 consulta médica domiciliar e 1 consulta de fisioterapia. Mas a fisioterapeuta não ia voltar mais e mandou a gente levar ela para fazer fisioterapia em um lugar longe e fora de mão, porque não dava para transportar ela. No segundo posto, teve uma consulta médica no posto durante o acolhimento, uma consulta da fisioterapeuta e uma da nutricionista. Ficou faltando a fono, e a enfermeira não ajudou com a escara. Nenhuma consulta deu muito resultado, no sentido de fazer muita diferença. Ela saiu do hospital melhor do que estava antes de morrer, com entendimento melhor, dado mais retorno. A gente conseguia dar alguns passos com ela, e isso tudo foi se perdendo com o tempo, com a falta de estímulo correto. Não sabíamos estimular corretamente, sem informação a gente fazia tudo no escuro, dando tiro no escuro. Ela foi atendida no UPA do Hospital Aparecida: atendimento péssimo também. Atendimento um pior que o outro. Sinceramente, o único local que ela teve atendimento bom, que lutaram pela vida dela, nos deram informação, foi no João XXIII [...]. (Trecho da entrevista da filha da paciente Maria, realizada em 31/05/2016).

O último trecho acima trata de uma retrospectiva da filha, realizada na última entrevista, ocorrida 1 mês após o falecimento da usuária. Trata-se da sua avaliação de todo o processo do cuidado, quando foi questionada se a mãe teve as necessidades de cuidados atendidas pelas equipes de saúde com as quais teve contato.

A análise desse caso nos faz questionar a capacidade da rede em oferecer acesso e garantir os cuidados que os usuários necessitavam. Essa situação é rotineira em grandes Hospitais. Há um momento em que, mesmo apresentando sequelas ou ainda necessitando de cuidados, esses não são mais de competência dos serviços hospitalares, não é mais necessária sua tecnologia nem a vigilância profissional 24 horas por dia. O usuário está pronto para continuar seu tratamento e sua reabilitação em outro nível da rede que lhe ofereça novas possibilidades e estímulos.

Ao retornarem ao seu território, em suas residências, as famílias estão cheias de expectativas e precisam lidar com o novo, as sequelas e as necessidades de reabilitação. A rede básica muitas vezes não consegue oferecer tais cuidados, a procura é bem maior que a oferta e os profissionais ainda estão despreparados para lidar com todo esse contexto social, econômico e estrutural.

Segundo a Política Nacional de Saúde da Pessoa Idosa, Brasil17, a família compartilha com a comunidade, a sociedade e o Poder Público a efetivação do direito à saúde do idoso. Nas situações já discutidas, em que o Estado não conseguiu prover todas as necessidades de saúde à usuária, a família se mostrou proativa e cuidadora, dentro das suas possibilidades. 
Por outro lado, como foi muito bem colocado por Merhy et al. ${ }^{4}$, as redes existenciais têm momentos estanques, em que as necessidades de saúde dos indivíduos não são atendidas, os espaços são obstaculizados, embarreirados e não há continuidade do cuidado. Esses são momentos de não rede, ausência de redes vivas.

As redes vivas são como malhas, não há início nem fim. Só há ligações e conexões. São circunstanciais e dependem de diversas situações e fatores a seu favor para serem redes vivas e possibilitarem o protagonismo do usuário e garantirem acesso e qualidade da assistência. Essas também podem ser redes mortas, que burocratizam e dificultam a resolução das necessidades de saúde da população ${ }^{4}$.

\section{Considerações finais}

As situações vividas pela usuária-guia e por seus familiares, sujeitos deste estudo, embora reflitam os problemas do cenário de saúde da nossa atualidade, não podem ser generalizadas em suas particularidades e analisadas como achados aplicáveis ao coletivo. Entretanto, os achados deste estudo trazem apontamentos e indicações que podem servir de fundamentos para se pensarem as políticas públicas em saúde e se realizarem propostas de planejamento e avaliação de programas, revisão de conceitos ou transformação de relações.

As redes vivas possibilitam a mobilidade do usuário que transversaliza a formalidade dos equipamentos instituídos, e, dessa maneira, o cuidado se dá a partir de encontros. O território das ações cuidadoras é de domínio de todos, trabalhadores da saúde, usuários e familiares. Assim, produzir atos de saúde cuidadores é tarefa a ser compartilhada por todos. E na relação trabalhador x usuário, todos podem acolher, escutar, interessar-se, contribuir para a construção de relações de confiança e conforto. E como cada qual faz esse movimento a partir um determinado ponto de vista, mobilizando saberes específicos e sabedoria adquiridos a partir de vivências concretas, o compartilhamento desses olhares certamente amplia e enriquece as possibilidades de compreender e comunicar-se com os usuários. Reconhece-se, também, que a construção de relações se dá em ato e nas circunstâncias específicas de cada encontro, que nos afetam de modo diferente a cada experiência.

Malta e Merhy ${ }^{\mathbf{1}}$ apontam que a fragmentação do cuidado e a falta de comunicação com a rede assistencial são fatores dificultadores para a realização da prática integral de saúde. Brito-Silva, Bezerra e Tanaka ${ }^{19}$ ressaltam que nenhum ator ou componente da rede dispõe da totalidade de recursos e competências necessárias para a solução dos problemas de saúde com garantia de cuidado integral e holístico, portanto, as soluções devem ser compartilhadas e discutidas em conjunto.

Pode-se relatar como síntese dos achados as fragilidades nos processos como um todo, resultando em ausência de integralidade no cuidado oferecido, já que a sua garantia está relacionada à oferta de ações de promoção da saúde, prevenção de agravos e reabilitação que transversalizem todos os níveis de atenção à saúde e complexidade, de maneira intersetorial, multiprofissional, interdisciplinar, de modo a garantir a continuidade do cuidado, atendendo a todos os tipos de necessidades que os sujeitos venham a apresentar.

Conclui-se este trabalho afirmando que a incipiência da vinculação entre usuária/familiares e equipe, assim como a fragmentação na transferência/continuidade do cuidado, são pontos muito importantes a serem demarcados para discussões futuras e destacam-se entre os achados, podendo ter contribuído para o desfecho do caso. É preciso investir na formação desses sujeitos trabalhadores e gestores para práticas integrais em saúde, acolhedoras e humanizadas, que considerem o usuário enquanto protagonista do seu cuidado, capaz de colocar suas demandas e de contribuir para a efetivação do cuidado a partir de sua atuação copartícipe, indo a favor da ruptura com o modelo biomédico vigente, que verticaliza e obstaculariza o cuidado. 


\section{Colaboradores}

Hadad ACAC contribuiu substancialmente para a concepção e o planejamento, para a análise e a interpretação dos dados, revisão e elaboração do artigo e aprovação da versão final. Jorge AO contribuiu substancialmente para a concepção e o planejamento, para a análise e a interpretação dos dados, revisão e elaboração do artigo e aprovação da versão final.

\section{Referências}

1. Pinheiro R, Guizardi FL, Machado FRS, et al. Demanda em Saúde e Direito à Saúde: Liberdade ou necessidade? Algumas considerações sobre os nexos constituintes das práticas de integralidade. In: Pinheiro R, Mattos RA, organizadores. Construção social da demanda: direito à saúde, trabalho em equipe, participação e espaços públicos. Rio de Janeiro: Uerj; Abrasco; 2005. p. 11-31.

2. Cecilio LCO. As necessidades de saúde como conceito estruturante na luta pela integralidade e eqüidade na atenção em saúde. In: Pinheiro R, Mattos RA, organizadores. Os sentidos da integralidade na atenção e no cuidado à saúde. Rio de Janeiro: Uerj; Abrasco; 2001. p. 113-26.

3. Merhy EE, Feuerwecker L, Gomes MPC. Da repetição à diferença: construindo sentidos com o outro no mundo do cuidado. In: Franco, TB, organizadores. Semiótica, afecção \& cuidado em saúde. São Paulo: Hucitec, 2010. p. 60-75.

4. Merhy EE, Gomes MPC, Santos MFL et al. Redes Vivas: multiplicidades girando as existências, sinais da rua. Implicações para a produção do cuidado e a produção do conhecimento em saúde. Rev. Divulgação em Saúde para Debate. 2014; 52:153-164.

5. Merhy EE, Cecílio LCO. A integralidade do cuidado como eixo da gestão hospitalar. Campinas: Unicamp; 2003. (mimeo).

6. EPS Em Movimento. Usuário guia. 2014 [acesso em 2015 out 21]. Disponível em: http://eps.otics.org/material/entrada-experimentacoes/arquivos-em-pdf/ usuario-guia.

7. Mattos RA. A integralidade na prática (ou sobre a prática da integralidade). Cad. Saúde Pública 2004; 20(5):1411-16

8. Araújo D, Miranda MCG, Brasil S. Formação de profissionais de saúde na perspectiva da integralidade. Rev. Baiana Saúde Pública 2007; 31 (supl1): 20-31.

9. Hadad ACAC, Jorge AO, Melo EM. Construção de Redes Vivas no Percurso de Vítimas de Trauma com Exigências de Cuidados Após Alta Hospitalar sob a perspectiva dos usuários e familiares. Rev Med Minas Gerais 2016; 26 (supl8): S107-S111. 
10. Moebus RLN, Merhy EE, Silva E. O Usuário-cidadão como guia. Como pode a onda elevar-se acima da montanha. In: Merhy EE, Baduy RS, Seixas CT, et al. organizadores. Avaliação compartilhada do cuidado em saúde: surpreendendo o instituído nas redes. Rio de Janeiro: Hexis; 2016. p. 43-53. (Políticas e cuidados em saúde; 1).

11. Bardin L. Análise de conteúdo. Lisboa, 70 edição; 1979.

12. Minayo MCS. O Desafio do Conhecimento: Pesquisa Qualitativa em Saúde. 7. ed. Rio de Janeiro: Hucitec-Abrasco; 2000.

13. Brasil. Ministério da Saúde. Secretaria de Atenção à Saúde. Política Nacional de Atenção Básica. Brasília, DF: Ministério da Saúde, 2012.

14. Veras RP, Caldas CP, Motta LB, et al. Integração e continuidade do cuidado em modelos de rede de atenção à saúde para idosos frágeis. Rev. Saúde Pública [internet]. 2014 [acesso em 2018 nov 25]; 48(2):357365. Disponível em: https://doi.org/10.1590/S00348910.2014048004941.

15. Lima RCD, Galavote HS, Schwartz TD, et al. Significando os sentidos da vida na formação dos profissionais de saúde: com a palavra os estudantes de enfer- magem da Universidade Federal do Espírito Santo. Cogitare Enferm. 2009; 16(1):167-70.

16. Cunha EM, Giovanella L. Longitudinalidade/continuidade do cuidado: identificando dimensões e variáveis para a avaliação da Atenção Primária no contexto do sistema público de saúde brasileiro. Ciênc. Saúde Colet., 2011, 16(supl1):1029-1042.

17. Brasil. Ministério da Saúde. Portaria no 2.528, de 19 de outubro de 2006. Aprova a Política Nacional de Saúde da Pessoa Idosa. Diário Oficial da União. 20 Out 2006. Seção 1, p. 142.

18. Malta DC, Merhy EE. O percurso da linha do cuidado sob a perspectiva das doenças crônicas não transmissíveis. Interface (Botucatu). 2010 [acesso em 2015 set 10]; 14(34):593-605 . Disponível em: http://www. scielosp.org/pdf/icse/v14n34/aop0510.pdf.

19. Brito-Silva K, Bezerra AFB, Tanaka OY. Direito à saúde e integralidade. 2012. [acesso em 2015 set 10]. Disponível em: http://www.scielosp.org/pdf/icse/ v16n40/aop1812.pdf.

Recebido em 03/04/ 2017

Aprovado em 04/12/2018

Conflito de interesses: inexistente

Suporte financeiro: não houve 